\title{
INCLUSÃO DO ALUNO SURDO NA PRÁTICA PEDAGÓGICA
}

\section{ARTIGO ORIGINAL}

CRUZ, Delzuita Santana ${ }^{1}$

SANTOS, Eliete Correia dos ${ }^{2}$

CRUZ, Delzuita Santana. SANTOS, Eliete Correia dos. Inclusão do aluno surdo na Prática Pedagógica. Revista Científica Multidisciplinar Núcleo do Conhecimento. Ano 05, Ed. 10, Vol. 12, pp. 137-155. Outubro de 2020. ISSN: 2448-0959, Link de acesso: https://www.nucleodoconhecimento.com.br/educacao/inclusao-do-aluno

\section{RESUMO}

Esta pesquisa aborda a inclusão do aluno surdo na prática pedagógica da escola pública. O objetivo geral é analisar como a escola trabalha a inclusão desse aluno e se os profissionais que atuam estão preparados para recebê-los. Os objetivos específicos são identificar as dificuldades encontradas pelos alunos surdos e pelos professores na sua atuação. Quais os mecanismos que eles desenvolvem no sentido de vencer estas dificuldades e compreender a importância de o aluno surdo estar em contato com outros surdos e ouvintes para o desenvolvimento social. Esta investigação foi de cunho descritivo exploratório, em uma abordagem qualitativa. Para colher a informação necessária optou-se pela observação seguida de questionário que foi enviado para 27 profissionais que lidam diretamente com alunos surdos, dentre eles direção, coordenação pedagógica, professores do ensino regular, professores e intérprete de LIBRAS, alunos surdos, alunos ouvintes e pais de alunos ouvintes.

\footnotetext{
${ }^{1}$ Mestrado em Ciências da Educação e Multidisciplinaridades; Especialista em Ensino de Língua Portuguesa; Graduada em Letras e Pedagogia.

2 Orientadora. Doutorado em Linguística. Mestrado em Linguagem e Ensino. Especialização em Planejamento e Gestão Escolar. Especialização em Língua Portuguesa. Graduação em Letras.
} 
Desses, somente 25 aceitaram participar. Os dados evidenciaram que as escolas em análise não dispõem de Intérprete de LIBRAS, e que os profissionais que atuam com os alunos surdos não têm conhecimento da Língua de Sinais para dar suporte a esses alunos em sala de aula. Nesta pesquisa evidencia que $8 \%$ dos profissionais possuem Pós-graduação em LIBRAS. 20\% possuem Pós-graduação em Letras, 20\% possuem Pós-graduação em Pedagogia, 8\% possuem Pós-graduação em História. 4\% possuem o Magistério com curso Tradutor/Intérprete em LIBRAS, 4\% possuem o Ensino Médio completo, 24\% estão cursando o Ensino Fundamental Anos Finais e 8\% possui o Ensino Fundamental Anos iniciais. Embora haja alguns profissionais com formação, entre os participantes, ainda não estão voltados, de fato, para a sua atuação como intérprete uma vez que, $88 \%$ dos entrevistados não possuem curso básico na área de LIBRAS. Conclui-se que o papel do intérprete é relevante no contexto educacional inclusivo. Nota-se que esse profissional participa diretamente do avanço dos alunos com surdez no processo de Ensino/aprendizagem.

Palavras-chave: Intérprete, aluno surdo, inclusão escolar, aprendizado.

\section{INTRODUÇÃO}

Nos últimos anos, tem havido mudanças significativas no que se refere à Educação Inclusiva. É uma busca constante entre familiares e profissionais da área que acreditam na potencialidade de um indivíduo que apresenta algum tipo de deficiência. O propósito dessas mudanças é garantir que a escola seja capaz de viabilizar o acolhimento e cultivar elementos de acesso a uma educação eficaz, uma vez que esses sujeitos são excluídos e não se enquadram naquele padrão de normalidade visto pela sociedade.

A Declaração de Salamanca (BRASIL, 1994, p. 3) nos comenta que "[...] no contexto desta estrutura, o termo 'necessidades educacionais especiais' refere-se a todas aquelas crianças ou jovens cujas necessidades educacionais especiais se originam em função de deficiências ou dificuldades de aprendizagem". A educação inclusiva envolve uma proposta, antes de tudo, de percepção política em que todo e qualquer cidadão ou cidadã devem estar engajados em prol de uma ação educativa que 
fortaleça vínculos entre todas as pessoas, independente de religião, raça ou gênero. Pensando em ações que reduzam a discriminação, assim como a exclusão e, que os acolha em todos os espaços sociais. Portanto, pensar em inclusão significa colocar em prática ações pedagógicas que garantam a participação de todos no ensino e aprendizagem.

Sob esta perspectiva, a surdez sempre foi motivo de preconceito e discriminação. As pessoas entendiam que 0 indivíduo surdo não deveria ser alfabetizado. Era considerado incapaz, sem direito algum. Sem condição de estabelecer qualquer tipo de comunicação. Com o surgimento da Língua de Sinais muitas mudanças aconteceram. A pessoa surda ganhou um novo contexto. Uma forma de se comunicar com o outro, seja ele ouvinte ou não. Essa habilidade foi ganhando forma a partir do interesse de familiares e amigos do indivíduo surdo.

A lei 10.436 de 24 de abril de 2002, que dispõe sobre a Língua Brasileira de Sinais, torna obrigatório o acesso das pessoas surdas nas Instituições Federias, garantindo comunicação, informação e educação nos processos seletivos, ocorridos em todos os níveis e esferas, desde a Educação Infantil até à superior. Sendo assim, a pessoa surda passou a ganhar mais espaço e mostrar, dentro da sua limitação, suas competências e habilidades na comunicação.

No decorrer dos anos, as escolas têm buscado adequar-se a essa realidade e buscar mecanismos que viabilizem o acesso do estudante surdo ao aprendizado. Isso só será possível por meio da Língua Brasileira de Sinais, transmitida através do intérprete ou professor de Libras.

Sendo assim, essa pesquisa aponta as dificuldades enfrentadas pelos profissionais da área de Libras, pelos indivíduos com surdez, pelos profissionais que lidam diretamente com eles e, consequentemente, pelos familiares dos surdos, assim como sugestões para a melhoria do trabalho desses profissionais.

Portanto, esta pesquisa tem como objetivo geral analisar como a escola trabalha a inclusão desse aluno e se os profissionais que atuam estão preparados para recebê- 
los, e propor ações mediadoras que possibilite aos docente a compreensão da Língua de Sinais assim como a Os objetivos específicos são: identificar as dificuldades encontradas pelos alunos surdos e pelos professores na sua atuação, quais os mecanismos que eles desenvolvem no sentido de vencer estas dificuldades e compreender a importância de o aluno surdo está em contato com outros surdos e ouvintes para o desenvolvimento social dele.

Esta pesquisa aconteceu com a participação de treze entrevistados, dentre eles, professores da Rede Regular, professora de Libras, Intérprete de Libras, alunos surdos e ouvintes e pais de alunos que atuam em escolas públicas do nordeste baiano. As informações para análise de dados, através de uma pesquisa de campo, foram colhidas por meio de observações dentro do espaço escolar, conversas informais com professores e funcionários das escolas em estudo. Foi aplicado um questionário com questões abertas, afim de que os participantes pudessem explanar suas experiências de forma livre e espontânea.

\section{A LÍNGUA DE SINAIS: CONTEXTO CONTEMPORÂNEO}

Aprender a categorizar o ensinamento de novos conceitos é uma tarefa difícil de ser aprendida, por vezes, que como observamos em Perrenoud (2000, p. 29), diferenciar o ensino "é fazer com que cada aprendiz vivencie, tão frequentemente quanto possível, situações fecundas de aprendizagem". Para que isso ocorra, é necessário que as mudanças aconteçam, de fato, no cenário educacional brasileiro. Vale salientar que, associar a prática pedagógica ao aprendiz não é, portanto, nem abdicar a instruilo, nem deixar de colocar em prática os objetivos necessários e sim, buscar mecanismos para que diminua a desigualdade no espaço escolar e, ao mesmo tempo, elevar o nível de ensino e aprendizagem do indivíduo com surdez.

Portanto, os professores envolvidos com uma nova política de inclusão têm mais facilidade em sensibilizar-se diante do fracasso de um indivíduo com necessidades especiais e defender o propósito de que o ensino para o aluno surdo deve ser mediado através do intérprete em sala de aula. A inquietação da pesquisadora em analisar a prática educativa para alunos surdos da escola em análise é, acima de tudo, igualar o 
ensino às características individuais de cada um, não surgiu somente dos respeito às pessoas, ela faz parte de uma exigência por igualdade diante da cultura, em desigualdade de aprendizagem e, posteriormente de êxito escolar. Aja visto que, os alunos surdos têm direito a uma inclusão adequada na escola em estudo. Eles precisam ter a garantia que, ao final de cada ano letivo, estejam preparados para uma nova etapa educacional.

No campo da educação tornou-se muito comum falar de sujeito, sujeito ativo, sujeito que constrói o seu próprio conhecimento e assim sucessivamente. $O$ que isso quer dizer? Morin (1996) propõe uma síntese instrutiva e auspiciosa diante da nação em foco, permitindo-nos compreender o processo de ensino e aprendizagem de forma a resolver grande parte das interrogações levantadas durante esta pesquisa.

Segundo Morin (1996), em se tratando de sujeito humano, revelam-se os três princípios desdobrados da nação autônoma dos sistemas: identidade, que oscila entre inclusão e exclusão, isto é, na capacidade de lidar com signos, índices, dados e informações. Essa capacidade tem, portanto, caráter cognitivo e é necessário a qualquer vivente. Se o individuo não computa, não identifica o que the é ou não compatível, falece, porque o cômputo quer dizer: coloque-me no centro do meu mundo, do mundo que conheço para tratá-lo, considerá-lo e para realizar todas as ações de salvaguarda, de proteção e de defesa.

A discussão sobre a noção de sujeito reúne elementos para abordamos o processo de ensino e aprendizagem tendo como foco a relação entre dois termos. Se nossa subjetividade é necessariamente construída nas relações sociais, a relação ensino e aprendizagem, sobre seu caráter de incerteza e sobre a comunicação e incomunicabilidade tão prováveis nas relações humanas e pedagógicas levam à dedução de que essa relação pode ou não ser dada. Portanto, o problema que se coloca para os profissionais de educação e para os proponentes e partidários de uma pedagogia inclusiva é, antes de tudo, como aumentar a probabilidade para que a relação de ensino e aprendizagem ocorra (GIUSTA; FRANCO, 2003). 
De acordo com Bordenave (1992) a interação do indivíduo com outras pessoas é fundamental para o seu crescimento pessoal e profissional no âmbito social. É a partir daí que esse indivíduo sente-se realizado e passa a observar o mundo de uma forma mais própria e particular e assim a sua evolução vai acontecendo.

O autor acima aborda que a exclusão leva o ser humano às margens da sociedade e, se tratando de escola, deve-se alertar para a autoexclusão, uma vez que, se os alunos surdos continuarem com os seus direitos negados, automaticamente eles se afastam do espaço educacional.

O aluno surdo sente-se inferior e incapaz. A falta de entendimento traz para ele insegurança, medo, sentimento de inferioridade e torna-os ansiosos.

Ser contrário à inclusão escolar de alunos com surdez é defender guetos normalizadores que, em nome das diferenças existentes entre pessoas com surdez e ouvintes, sectarizam, homogeneízam a educação escolar. As pessoas com surdez e/ou alguns profissionais que atuam na sua educação, em alguns momentos, usam o discurso multicultural, defendem as identidades não fixadas, o pluralismo cultural, mas, enfatizam as relações de poder de um grupo majoritário de ouvintes sobre o grupo minoritário de pessoas com surdez. A escolaridade guetificada tem sido defendida, pautada em cultura, língua e comunidade próprias para as pessoas com surdez e que essa posição se baseia em teorias que estão camuflando a visão segregacionista em nome das diferenças. (DAMÁZIO, 2005, p.12).

É preciso pensar na educação numa perspectiva complexa, capaz de compreender e viver a solidariedade em diversas dimensões e sob os mais variados e múltiplos aspectos também dentro da escola, partindo do processo auto-eco-organizador, com base em métodos que todo e qualquer sujeito esteja apto a desenvolver de acordo com as limitações individuais de cada um.

Ainda existem situações que nos leva a crer que a escola ainda não definiu o seu papel no contexto histórico, social e político, principalmente quando o assunto é a acessibilidade.

Sabe-se que o aluno surdo não aprende ouvindo e sim através de sinais, o que chamamos de linguagem gestual. Sendo assim, compreende-se que, a educação para 
pessoas com surdez passa por processos, de acordo com as abordagens de Bouvet (1990), que enfatiza que o aluno surdo precisa ter um ensino bilíngue. Primeiro ele aprende a Língua de Sinais (Libras), para depois aprender a Língua Brasileira (Língua Pátria). Nenhuma criança nasce conhecendo a Língua de Sinais. Porém, essa necessidade de que precisa aprender a Língua de Sinais, deve partir da escola. Por isso, surge a inquietação, como é a educação do surdo na Escola José Bonifácio? Como é possível que o aluno surdo aprenda algo sem uma intérprete em sala de aula, sem esse aluno conhecer a Língua de Sinais?

Segundo Quadros (2006, p. 15), "a Língua de Sinais Brasileira, Língua que é o meio e o fim da interação social, cultural e científica da comunidade surda no Brasil, é uma Língua visual-espacial".

Assim, de acordo com o pensamento acima, a Língua de Sinais precisa ser considerada uma Língua Natural ou sistemas linguísticos específicos que a diferencie dos demais sistemas de comunicação.

As línguas de sinais são, portanto, consideradas pela linguística como línguas naturais ou como um sistema linguístico legítimo, e não como um problema do surdo ou como uma patologia da linguagem. Stokoe, em 1960, percebeu e comprovou que a língua de sinais atendia a todos os critérios linguísticos de uma língua genuína, no léxico, na sintaxe e na capacidade de gerar uma quantidade infinita de sentenças. (QUADROS E KARNOOP, 2004, p. 30).

A respeito de a Língua de Sinais ser como outra língua qualquer, "sendo comparável em complexidade e possui seus valores e aspectos gramaticais diferenciados das outras Línguas" (ibidem, p.13). Sendo assim, compreende-se que a Língua de Sinais tem funcionamento como qualquer outra língua. É uma língua viva, rica e completa. Viva por possuir conhecimentos linguísticos da Língua de Sinais pelas pessoas surdas e evoluir diariamente. A autora Felipe (1997, p. 81) relata que "como toda língua, as línguas de sinais aumentam sues vocabulários com novos sinais introduzidos pelas comunidades surdas em respostas às mudanças culturais e tecnológicas". 
Os autores Pimenta e Quadros (2010), chamam atenção para um fato importante em relação às mudanças de sinais que acontecem no Brasil. Relatam que os sinais mudam na história.

A Lei 10436 de 2002, reconhece que a Língua de Sinais não pode substituir a Língua Portuguesa. A recomendação é que sejam trabalhadas as duas Línguas, porém, sendo a Libras a Língua principal no contexto escolar do aluno surdo. Por isso, é considerado que aprender as duas línguas é um avanço considerável para que aconteça a inclusão entre a comunidade surda e os ouvintes.

No processo de inclusão da educação dos surdos, não se pode levar em consideração somente partindo do ponto de vista linguístico, mas também o sócio-político e cultural. É importante que a comunidade ouvinte compreenda que os surdos identificam e percebem o mundo através do olhar. De acordo com Góes (2000, p. 31), "a produção de significado em relação ao mundo da cultura e a si próprio é um processo necessariamente mediado pelo outro, é efeito das relações sociais vivenciadas através da linguagem".

Segundo Brito (2003 p. 87)

Além da função comunicativa, as línguas naturais têm a importante função que é a de suporte linguístico para a estruturação do pensamento. Esta última, frequentemente é ignorada por especialistas envolvidos na educação do surdo que consideram a língua apenas como meio de comunicação. [...] As Línguas de Sinais, por serem naturais e de fácil acesso para os surdos, são extremamente importantes para o preenchimento da função cognitiva e suporte do pensamento.

A Língua de Sinais (LS) é a Língua natural da comunidade surda. Ela contém regras morfológicas, sintáticas, semânticas e permite que o aluno surdo avance o seu cognitivo. É uma Língua completa e possui suas próprias estruturas.

Porém, ainda existem pessoas que não levam esses conceitos em consideração. Entendem que a LS é uma língua restrita apenas ao desenvolvimento social e cognitivo do indivíduo surdo. 
De acordo com os relatos de Lodi, Harrison e Campos (2002)

Embora, muitas vezes, se aceite a língua de sinais como língua em circulação no ambiente escolar, ela é vista como prática de interação entre pares, para trocas de experiências cotidianas e informais, e não como língua em uso para as práticas de ensino. Desvaloriza-se aquilo que o surdo tem a dizer, da forma como o diz. Esclarecemos. A língua de sinais não é considerada como própria para o desenvolvimento e a apropriação dos conhecimentos veiculados social e culturalmente e nem tampouco para se ter acesso à língua portuguesa. (LODI; HARRISON E CAMPOS 2002, p. 40).

E dessa forma, de acordo com a pesquisa, nota-se que as maiores dificuldades que existem para o cumprimento da Portaria 1.793/94 do MEC, está na falta de profissionais capacitados para atuarem na área. Assim, para garantir o processo de Inclusão na Escola em análise é necessário investir na formação continuada e utilizar recursos que contribuam com o aprendizado dos alunos com deficiência. Segundo Montoan (2003), que chama atenção para a importância em investir na formação continuada dos profissionais que atuam no contexto educacional inclusivo "ensinar, na perspectiva inclusiva, significa ressignificar o papel do professor, da escola, da educação e de práticas pedagógicas que são usuais no contexto excludente do nosso ensino, em todos os seus níveis" (MONTOAN, 2003, p. 81).

Lima (2006, p. 122), relata que "é essencial que os professores reconheçam sua própria importância no processo de inclusão, pois a eles cabe planejar e implementar intervenções pedagógicas que deem sustentação para o desenvolvimento das crianças". A autora afirma que o processo de inclusão depende da atuação e das ações dos professores em sala de aula.

Algumas pesquisas começam a despertar no Brasil, apresentando resultados sobre as funções deste profissional no espaço escolar e o que tem sido reportado é que, apesar do intérprete romper uma barreira comunicativa na rede regular de ensino, as questões metodológicas deixam a desejar, ignorando aspectos culturais e sociais que fazem parte do processo educacional, deixando, muitas vezes, a criança surda à margem da Escola. (QUADROS, 2006, p. 144).

Por volta dos anos vinte no século passado, Vygotsky escreveu um texto que relatava a questão educacional da criança com surdez. Ele afirma que os obstáculos 
decorrentes das dificuldades em ouvir o outro, desencadeiam motivações para a formação de outras maneiras de funcionamento e essas motivações originam-se das relações sociais e das necessidades, podendo seguir a mecanismos que estabeleça o desempenho no procedimento que as pessoas desenvolvem na relação com o outro que, por ventura, podem se estabelecer em um crescimento pessoal e social (VYGOTSKY, 1989). Compreende-se, portanto, que a escola pode ser um espaço de aprendizado privilegiado para o desenvolvimento intelectual do cidadão.

Incluir não é apenas agregar o aluno surdo no espaço escolar. O processo de inclusão deve ser compreendido como uma ação que atenda à diversidade, que contemple o conhecimento e as especificidades desse aluno. Embora os alunos surdos da Escola em análise recebam o carinho, o respeito e o acolhimento por parte de alguns colegas, professores e dos envolvidos no contexto escolar, ainda é necessário buscar o conhecimento que auxilie o trabalho e que seja pautado no desempenho individual de cada um desses alunos, para, a partir daí, tornarem-se cidadãos preparados para viverem em sociedade. O Decreto $n^{-0} 5.626 / 05$ (BRASIL, 2005) relata com muita clareza, no Artigo 14, capítulo IV, Inciso II, que se deve

ofertar obrigatoriamente, desde a Educação Infantil, o ensino de Libras e também da Língua Portuguesa, como segunda língua para alunos surdos", bem como no inciso $\mathrm{V}$, que relata o dever de "apoiar, na comunidade escolar, o uso e a difusão de Libras entre professores, alunos, funcionários, direção da escola e familiares, inclusive por meio da oferta.

Embora tudo isso esteja respaldado em Leis e Decretos citados acima, e mais, com a Lei 10.098 de 19 de dezembro de 2000, que estabelece a acessibilidade nos sistemas de comunicação e sinalização, ainda é necessário e emergente, desfazer alguns conceitos que estão entranhados no meio social entre surdos e ouvintes.

Assim, os profissionais e familiares de alunos surdos, necessitam procurar conhecer mais a Língua de Sinais para melhorar esses conceitos de forma mais reflexiva, e entender a amaneira como as experiências visuais dos surdos acontecem no contexto sociocultural. As pessoas precisam compreender que, todo indivíduo, com limitações ou não, devem ter a oportunidade de construir a sua própria identidade. Isso se dá 
através da escola, como professores conhecedores de Língua de Sinais, que tenham interesse em contribuir para o crescimento do aluno surdo por meio da melhoria de um trabalho realizado em sala de aula e com muito êxito.

\section{RESULTADOS ENCONTRADOS}

De acordo com os resultados da pesquisa, os indivíduos surdos das escolas em análise não têm intérprete em sala de aula. A professora de Libras atua também como intérprete para não deixar esses alunos sem o principal mecanismo de mediação entre eles e o conhecimento. A aluna surda de 04 anos de idade, por exemplo, não tem intérprete em sala de aula e, consequentemente, causa inquietação e desconcentração também, nos alunos ouvintes.

Neste ponto, abordaremos o grau de qualificação educacional dos profissionais entrevistados nesta pesquisa, tentando compreender e comparar os dados apresentados com as necessidades descritas até agora acerca da abordagem dada aos alunos surdos nas escolas públicas. A tabela que segue, aborda a formação do profissional de educação e o percentual de acordo com as respostas dos entrevistados.

TABELA 1 - Formação dos profissionais entrevistados (Quant./\%)

\begin{tabular}{|l|l|}
\hline Pós-graduada em LIBRAS & 2 / 8\% \\
\hline Pós-graduada em Letras & $5 / 20 \%$ \\
\hline Pós-graduada em Pedagogia & $5 / 20 \%$ \\
\hline Pós-graduada em História & 2 / 8\% \\
\hline Magistério - Tradutor/Intérprete em LIBRAS & $1 / 4 \%$ \\
\hline Ensino Medio complete & $1 / 4 \%$ \\
\hline Ensino Fundamental anos finais - cursando & $6 / 24 \%$ \\
\hline Ensino Fundamental anos iniciais & $2 / 8 \%$ \\
\hline
\end{tabular}

Fonte: Dados da pesquisa (2016). 
De acordo com o gráfico acima, percebe-se que dos vinte e cinco profissionais entrevistados que atuam diretamente com alunos surdos no contexto educacional, dois (8\%) possuem pós-graduação em Libras; um (4\%) possui apenas Magistério com o curso de tradutor/intérprete de Libras; cinco (20\%) possuem pós-graduação em Letras; cinco (20\%) possuem pós-graduação em pedagogia; dois (8\%) possui pósgraduação em história. Dos seis alunos entrevistados, três surdos e três ouvintes, todos são estudantes do 9ํ Ano do Ensino Fundamental. Os pais dos alunos surdos, também entrevistados, dois possuem apenas a antiga $4^{a}$ série do Ensino Fundamental e uma mãe possui o Ensino Médio Completo.

Baseando-se nas descrições acima, apenas $12 \%$ dos entrevistados possuem cursos na área de Libras. Os $88 \%$ dos profissionais entrevistados que atuam diretamente com alunos surdos da escola em análise, não possuem formação acadêmica em Língua de Sinais.

Diante dessa realidade percebe-se que, embora haja uma profissional com formação acadêmica na área de Libras no contexto educacional das escolas em análise, ainda há um déficit muito grande de profissionais especializados para atuarem em sala de aula de aluno com surdez. Essa defasagem ocorre, principalmente, por falta de profissionais qualificados na área e Libras e, a falta de investimento do poder público. O governo Federal, através do MEC, oferece cursos de Licenciatura em Letras/Libras, cabe ao município investir nessa área e criar políticas de incentivo de conscientização para que a pessoa ouvinte sensibilize-se diante do indivíduo com necessidades educacionais especializadas e assim, amenize os problemas e dificuldades que os surdos enfrentam dentro das Instituições de Ensino e fora dela.

Porém, nota-se que uma das dificuldades em incluir o aluno surdo na prática pedagógica das Escolas em análise está principalmente, na falta de profissionais qualificados para atuarem com esse público, já que o município de Araci/BA, de acordo com os dados obtidos através da Secretaria Municipal de Educação, não dispõe de pessoas para trabalharem com o aluno. 
Dessa forma, conclui-se que os alunos com surdez ainda estão às margens da sociedade, ou seja, o processo de inclusão está apenas na teoria, enquanto na prática esse aluno não tem o mínimo de seus direitos garantidos. Há uma grande necessidade de se ter pessoas qualificadas para essa área. A sociedade ouvinte precisa compreender a importância da formação continuada em Língua de Sinais para facilitar a acessibilidade da pessoa surda em qualquer ambiente social. Para o surdo o conhecimento só acontece por meio dos sinais. E esses sinais são transmitidos através das mãos das pessoas que desejam essa profissão que exige cuidado e acima de tudo muita dedicação.

A seguir, falaremos sobre os cursos de formação continuada na área de Libras dos profissionais de educação entrevistados para a realização dessa pesquisa.

TABELA 2 - Possui algum curso de formação continuada na área de Libras

\begin{tabular}{|l|l|}
\hline CURSO BÁSICO DE $4 \mathrm{~h}$ & $8 \%$ \\
\hline CURSO BÁSICO DE 12h & $4 \%$ \\
\hline NÃO POSSUI & $88 \%$ \\
\hline
\end{tabular}

Fonte: Dados da pesquisa (2016).

De acordo com a tabela acima, diante de dez professores entrevistados da Rede Regular de Ensino que lidam diretamente com alunos surdos em sala de aula, $8 \%$ tem curso básico de apenas $4 \mathrm{~h}$ e $4 \%$ possuem curso básico com duração de 12h, porém, segundo relatos, não é suficiente para que aconteça a comunicação entre eles e o surdo. Percebe-se que na escola em análise, $88 \%$ dos profissionais não possuem formação qualificada para atuar nesse contexto.

Segundo Edler Carvalho (2000, p. 147) "[...] os professores devem desenvolver competências para a prática alternativa e para todos os procedimentos didáticopedagógicos necessários para prover a inclusão". A importância do conhecimento básico sobre indivíduos com alguma deficiência e que os docentes que atuam em espaço com ofertas de inclusão precisam ter domínio. 
Quadros (2006) afirma que a inclusão depende de diversos fatores que estão além dos aspectos considerados legais. Para ela, esse processo sofre influências de cunho político e econômica. São questões que desencadeia, sobretudo, nos professores que atuam na área e que estão em formação profissional. Para a autora, a inclusão ainda é bastante lenta diante das demandas existentes na sociedade. Ela cita como exemplo o relato do professor intérprete de Língua de Sinais.

$\mathrm{Na}$ segunda parte do questionário, aborda o ponto de vista que os participantes relatam a respeito do aluno surdo no contexto escolar, contando com um índice de satisfação de irrisórios $2 \%$, contra $98 \%$ de insatisfação por parte de todos os entrevistados participantes da pesquisa em questão.

De acordo com o resultado, a escola aceita o aluno surdo, mas não dá suporte que possa garantir um aprendizado relevante para a sua vida social. Percebe-se, porém, que a função comunicativa desse aluno, que é a principal responsável pelo aprendizado do surdo, não acontece.

De acordo com a resposta da questão 6 do questionário aplicado ao aluno surdo, que perguntava se o aluno conseguia compreender a aula sem a presença da intérprete, apenas com o professor da rede regular? Todos foram unânimes em responder que não conseguiam compreender a aula.

Sem a intérprete em sala de aula não há aprendizado. Se não há aprendizado, não há inclusão. Esse profissional é responsável por intermediar o contato entre o aluno surdo e o professor, assim como, entre os colegas de sala e toda comunidade escolar.

Dessa forma, conclui-se que esse aluno não está incluído na prática pedagógica da escola em análise da forma que deveria ser, pois além de não oferecer uma intérprete de Libras, ainda não dispõe de material didático adequado para que a professora de Libras possa fazer as adaptações necessárias para o atendimento com esse aluno na sala AEE, local reservado para no espaço da escola para atendimento ao aluno com dificuldade educacional especializada. 
Baseando-se nos relatos exposto, concordo com o percentual relatado em que $98 \%$ dos entrevistados afirmam que a escola não atende as necessidades específicas do aluno surdo.

\section{SOCIABILIDADE DO ALUNO SURDO NO AMBIENTE ESCOLA}

Nas tabelas a seguir, tentaremos observar a relação de convívio do aluno surdo com os outros alunos, buscando para isso, trechos e indagações da própria pesquisa, que serviram de base qualitativa para a construção das tabelas e a formulação dados que descrevem como está o pensamento e a atitude daqueles que trabalham e vivenciam o caminhar educacional dos alunos surdos.

Tabela 3 - Convívio do aluno ouvinte com o aluno surdo

\begin{tabular}{|l|l|}
\hline ENTREVISTADOS & $\begin{array}{l}\text { Como se dá a relação de interação entre o aluno surdo e } \\
\text { os outros alunos }\end{array}$ \\
\hline PROFESSOR & $\begin{array}{l}\text { Foi comentado que alguns alunos recebem bem o aluno } \\
\text { surdo, mas às vezes deve-se chamar a atenção dos } \\
\text { outros alunos quanto ao posicionamento de respeito para } \\
\text { com os alunos surdos. }\end{array}$ \\
\hline $\begin{array}{l}\text { PROFESSOR DE } \\
\text { LIBRAS }\end{array}$ & $\begin{array}{l}\text { Alcançasse uma boa convivência quando o aluno surdo } \\
\text { se impõe e exige respeito }\end{array}$ \\
\hline $\begin{array}{l}\text { DIREÇÃO/ } \\
\text { /COORDENAÇÃO }\end{array}$ & $\begin{array}{l}\text { Às vezes é preciso chamar a atenção dos outros alunos } \\
\text { quanto à questão disciplinar a respeito do contato com o } \\
\text { aluno surdo. }\end{array}$ \\
\hline $\begin{array}{l}\text { ALUNO OUVINTE } \\
\text { ALUNO SURDO }\end{array}$ & $\begin{array}{l}\text { Alguns alunos se dão bem com eles, outros não. } \\
\text { gente. }\end{array}$ \\
\hline $\begin{array}{l}\text { PAIS DO alunos nos respeitam, outros não gostam da } \\
\text { SURDO ALUNO }\end{array}$ & $\begin{array}{l}\text { É uma questão de se respeitar o próximo, que nem todos } \\
\text { fazem. }\end{array}$ \\
\hline
\end{tabular}

Fonte: Dados da própria pesquisa (2016). 
Ao dirimirmos acerca do posicionamento da Tabela 3, podemos inferir alguns dados que ensejam um olhar a mais sobre a pesquisa em questão. Quando se questiona a respeito da relação e do convívio dos alunos surdos com os outros alunos ouvintes, obtivemos uma convergência de opiniões que se pautaram, sob algumas das óticas, em uma boa convivência entre os alunos surdos e os alunos ouvintes, em que, diante de certas situações, os alunos ouvintes necessitam às vezes, serem chamados a atenção, pois em alguns casos, surgem comentários preconceituosos, que denigrem a imagem do surdo, resultantes da falta de respeito e da intolerância. Esse pequeno contexto de preconceito, mesmo que isolado, deve ser entendido como algo que macule a boa convivência entre qualquer indivíduo, independente de suas características ou estado físicos.

Desse modo, e ainda analisando a Tabela 3, averiguamos que as respostas sobre a questão levantada na pesquisa sobre a relação e a interação entre os alunos ouvintes e os alunos surdos, quando perguntados aos professores, à direção/vice direção/coordenação, colocou-se muito em foco o fato do aluno ouvinte estar sempre sendo chamado à atenção em relação ao seu comportamento diante do seu colega com deficiência auditiva. Muitos desses conflitos surgem por diversos fatores, mas o comum entre esse problema ainda é o preconceito com a pessoa portadora de algum cuidado especial.

Em outra análise, agora com os professores de Libras, os alunos ouvintes e surdos, e os pais dos alunos surdos. Sentimos uma convergência de opiniões acerca dessa questão abordada, porém levantou-se também outro ponto de vista, em que o aluno surdo também é construtor de sua situação social. É através dele e de suas atitudes, que o convívio cotidiano molda-se e as diferenças podem ser diminuídas, as dificuldades amenizam-se e o preconceito pode ser modificado como um conceito novo.

A abordagem, aqui inserida, para esse questionamento, deixou bastante clara sua posição quanto aos mecanismos de interação e convívio presentes no ambiente escolar, entre os alunos surdos e os alunos ouvintes. Carece-se de mais aplicação e construção diária para essa interação. $O$ fato de ainda existirem conflitos que 
exprimam preconceito e intolerância, mesmo que isolados, demonstra ainda um grande caminho de maturidade social e cultural que nossa sociedade ainda deverá percorrer.

Tabela 4 - Relação social do aluno surdo dentro do ambiente escolar

\begin{tabular}{|c|c|c|}
\hline DOS & & $\begin{array}{l}\text { Como se dá a vida social do aluno surdo dentro do } \\
\text { ambiente escolar }\end{array}$ \\
\hline PROFESSOR & & $\begin{array}{l}\text { - Muito boa. Os alunos surdos sabem interagir bem com } \\
\text { os seus colegas e com o cotidiano da escola, adaptam- } \\
\text { se da forma que podem; } \\
\text { - Não se dão extremamente bem, às vezes ficam pelos } \\
\text { cantos do colégio. }\end{array}$ \\
\hline $\begin{array}{l}\text { PROFESSOR } \\
\text { LIBRAS }\end{array}$ & $\mathrm{DE}$ & $\begin{array}{l}\text { Ainda precisa melhorar e muito. O surdo não se sente a } \\
\text { vontade quando não entende o contexto do lugar. }\end{array}$ \\
\hline $\begin{array}{l}\text { DIREÇÃO/ } \\
\text { /COORDENAÇÃO }\end{array}$ & VICE & $\begin{array}{l}\text { Ficam um pouco distantes dos colegas ouvintes. } \\
\text { Preferem, na maioria das vezes ficarem juntos, porque } \\
\text { temos muitos alunos surdos no colégio. }\end{array}$ \\
\hline JVINIE & & \\
\hline
\end{tabular}

Fonte: Dados da própria pesquisa (2016).

Diante da Tabela 4, o questionamento acerca do ambiente social que o aluno surdo convive dentro da escola, levou a outro questionamento que deu abertura para uma discussão mais aprofundada sobre o assunto.

Com a análise dos questionários pesquisados, observou-se uma pequena divergência sobre as observações inqueridas nas respostas dos entrevistados. Professores relatam que a convivência do aluno surdo no ambiente escolar é boa, e eles sabem interagir com os outros alunos, mesmo diante de suas limitações; já o professor de Libras defende um ambiente melhor, em que o surdo sinta-se mais inserido dentro do contexto escolar; enquanto a direção/vice direção/coordenação, relatam que os 
alunos surdos, em grande parte das vezes, ficam sempre juntos, já que o colégio possui muitos alunos surdos; e os alunos ouvintes relatam que às vezes os alunos surdos ficam perto deles, e em outras vezes não.

Ao analisarmos os questionamentos pesquisados, inferimos um diálogo acerca da divergência de opiniões sobre o tema em questão, que coloca o aluno surdo em uma dicotomia em relação ao seu convívio no ambiente escolar. Ao observarmos esse impasse, chegamos à conclusão de que essa visão plural tem correspondência com a própria inserção do aluno surdo dentro do ambiente escola, que sob a visão de um professor que o insere em suas aulas da forma como o enxerga como um aluno com limitações, e não como um aluno que necessita de contextualização, fazendo dele um veículo que deve interagir para aprender, e não se inserir em todo o ambiente para compreender o processo interacional.

$\mathrm{Na}$ visão direção/vice, direção/coordenação, que participa da gestão escolar e educacional desse aluno surdo à margem de suas necessidades, enxerga-o muitas vezes como um problema a ser resolvido, ou uma lei que deva ser respeitada e adequada ao convívio escolar. Já com os alunos ouvintes, o entendimento do questionamento observado em suas respostas confere o único ponto que não converge com suas opiniões, na pesquisa. Continuam a pontuar que os seus colegas surdos ainda separam-se muito deles e que por vezes chegam-se para interagir, mas não muito.

Diante desse exposto, não relacionar o ambiente educacional com o ambiente social que vivemos é não se inserir como potencializador de nossos atos. Entender que o aluno surdo vive e convive dentro e fora da escola é o mínimo que devemos entender para começarmos a compreender que o aluno surdo é produtor de sua própria interação, e o meio educacional deve ser seu incentivador principal, no que tange ao convívio coletivo de aprendizagem. Mas, isso só é possível quando o compromisso é abraçado por todos, da direção e coordenação à secretaria de educação, dos professores (Libras ou não) aos alunos ouvintes, dos pais aos governantes. 
Dessa forma, surgem vários questionamentos. Até quando vamos fechar os olhos para essas pessoas? Porque que os ouvintes se comportam diante da pessoa surda como se ela fosse incapaz? Diante da experiência vivida com os alunos surdos durante a realização desta pesquisa pude perceber o quanto eles são prestativos, carismáticos e muito atenciosos quando eles percebem que se está ao lado deles.

Durante o questionário aplicado à equipe diretiva da escola em análise, no momento em que se perguntam quais os entraves que a escola enfrenta com relação à inclusão, a resposta é unânime, a falta de material pedagógico e humano para acompanhar o desempenho desses alunos. Esse relato confirma o desabafo da mãe da aluna surda. Isso comprova que, nos dias de hoje, ainda carregamos reflexos do passado, em que a pessoa surda era impossibilitada de ter os mesmos direitos tal qual uma pessoa ouvinte.

Ainda durante a aplicação do questionário à equipe diretiva da escola em análise, relata que o aluno surdo não consegue um bom aprendizado por falta de acompanhamento especializado. Em uma visita à Secretaria Municipal de Educação, em conversa com a coordenadora pedagógica, ela afirma que Araci/BA não dispõe de pessoas capacitadas para atender a demanda.

\section{CONCLUSÕES}

Um dos problemas encontrados nesta pesquisa foi a falta de pessoas qualificadas em Língua de Sinais, uma vez que o município dispõe apenas de 2 intérpretes e 1 professora de LIBRAS para atender a demanda da Educação. A falta de interesse da sociedade em buscar estudar e valorizar a Língua de Sinais, os professores que atuam diretamente com alunos surdos não conhecem e não têm interesse em conhecer a Língua de Sinais, foram outros pontos também bastante significativos.

A escola entende que incluir os alunos surdos resume-se apenas em recebê-los em sala de aula sem se preocupar se esse aluno compreende ou não a sua aula, apenas oralizada. Para esses profissionais, o papel de incluir fica apenas com a professora de Libras, enquanto que, o papel dessa professora é de transmitir aula de Libras para 
que o aluno surdo consiga compreender o que a intérprete transmite para ele em sala de aula, embora ela atenda, também, como intérprete.

O intérprete é o instrumento de sustentação nas instituições de Ensino, pois são eles os mediadores entre a comunicação do surdo com o ouvinte. É através dela que o surdo consegue se envolver nas atividades práticas e escritas em sala de aula. $\mathrm{O}$ professor do aluno surdo quando necessita falar algo para ele, chama a professora/intérprete para fazer a mediação, mesmo não estando no contexto de sala de aula. Dessa forma, esse profissional não atua apenas para interpretar conteúdos e sim de mediar em qualquer momento em que ela esteja presente.

Contemplando a relevância de todos os relatos citados, é necessário enfatizar que este trabalho ocorreu com o objetivo de analisar a Inclusão do aluno surdo na prática pedagógica e conscientizar os profissionais da escola em análise, assim como o poder público sobre a importância desse aluno manter-se em contato com outros surdos e ouvintes para o desenvolvimento social e profissional e, para que isso aconteça na prática, é importante que todos estejam engajados nessa luta, principalmente, buscar uma formação na área de LIBRAS a partir da disciplina em que atua. Quando todos estiverem conscientes ficará mais fácil sensibilizar o poder público no sentido de promover políticas de inclusão que contemple o aluno surdo, dessa forma, todas as escolas seriam contempladas e a inclusão de fato aconteceria.

Nesse sentido, para que o aluno surdo alcance um aprendizado significativo, pautado em direitos por uma educação de qualidade, é necessário que se crie ações que contemplem todo o contexto social em que ele está inserido. É nesse devemos refletir a cerca da educação do surdo. Com a expectativa de desenvolver conhecimento que garanta o aprendizado do aluno surdo em todas as esferas.

A educação do aluno surdo no contexto educacional precisa ser repensada a partir de uma nova perspectiva. Todos os envolvidos nesse contexto precisam compreender que é necessário o "respeito às diferenças", principalmente no aspecto linguístico, tentando encontrar mecanismos que auxiliem na prática educativa de inclusão. Uma 
prática de inovação que carece ser inserida nas novas atitudes de educar e incluir da escola em estudo.

\section{REFERÊNCIAS}

BORDENAVE, Juan E. D. O que é comunicação? ed. 15. São Paulo: Brasiliense, 1992.

BOUVET, D. The path to language: bilingual education for deaf children. Cleveland: Multilingual Matters, 1990.

BRASIL. PRESIDÊNCIA DA REPÚBLICA, Decreto no $\mathbf{5 . 6 2 6}$ de 22 de dezembro de 2005. Regulamenta a Lei 10.436 de 24 abr. 2002, que dispõe sobre a Língua Brasileira de Sinais, D.O.U de 23 dez. 2005, Brasília.

BRITO, L. F. Integração social \& educação de surdos. Rio de Janeiro: Babel, 2003.

DAMÁZIO, Mirlene. Educação escolar de pessoa com surdez: uma proposta inclusiva. 2005. Disponível em: <http://www.bibliotecadigital.unicamp.br/ document/?code=vtls000374273.> Acesso em: 20 jul. 2009.

GIUSTA, Agnela da S; FRANCO, lara M. Educação à Distância: uma articulação entre a teoria e a prática. Belo Horizonte: Editora PUC Minas, 2003.

LIMA, Priscila Augusta. Educação Inclusiva e Igualdade Social. São Paulo. Avercamp, 2006.

LODI, A. C. B.; HARRISON, K. M. P.; CAMPOS, S. R. L. Letramento e surdez: um olhar sobre as particularidades dentro do contexto educacional. In: LODI, A. C. et al. (Orgs.). Letramento e minorias. Porto Alegre: Mediação, 2002.

MONTOAN, Maria Tereza Égler. Inclusão Social: o que é? Por quê? Como fazer? São Paulo: Moderna, 2003. 
MORIN, Edgard. A noção do sujeito. In: SCHNITMAN, DF. (Org.). Novos paradigmas, cultura e subjetividade. Porto Alegre: Artes Médicas, 1996.

PERRENOUD, Philippe. Dez novas competências para ensinar. Porto Alegre: Artmed, 2000.

QUADROS. Políticas linguísticas e educação de surdos em Santa Catarina: espaço de negociações. Cad. CEDES. v. 26, n. 69, 2006.

. Educação de Surdos: efeitos de modalidade e práticas pedagógicas. In: Artigo publicado no livro pós-congresso "Temas em Educação Especial IV". EDUFS Car. 2010. Disponível em <http://www.ronice.ced.ufsc.br/ publicacoes/edu_surdos.pdf> Acesso em 21 ago. 2010.

QUADROS, R. M. de \& KARNOPP, L. Língua de sinais brasileira: estudos linguísticos. Art Med. 2004.

SANTOS, Roseli Albino dos. A trajetória de alunos deficientes mentais em classes especiais da rede pública estadual paulista. (Dissertação de Mestrado). São Paulo: Imprensa oficial, 2002.

VIGOTSKY, L.S. El nino ciego. In: obras completas. Tomo V. Habana: Cuba, 1989.

Enviado: Outubro, 2020.

Aprovado: Outubro, 2020. 